\title{
Advances in Metallic Materials Processing
}

\author{
Jyotsna Dutta Majumdar, ${ }^{1}$ Igor Smurov, ${ }^{2}$ Shoujin Sun, ${ }^{3}$ and Indranil Manna ${ }^{1,4}$ \\ ${ }^{1}$ Department of Metallurgical and Materials Engineering, Indian Institute of Technology, Kharagpur 721302, West Bengal, India \\ ${ }^{2}$ Laboratory of Diagnostics and Engineering of Industrial Processes (DIPI Lab), Ecole Nationale d'Ingénieurs de Saint-Etienne (ENISE), \\ 58 rue Jean Parot, 42023 Saint-Etienne, France \\ ${ }^{3}$ Faculty of Engineering and Industrial Sciences, Swinburne University of Technology, Melbourne, VIC 3122, Australia \\ ${ }^{4}$ Central Glass and Ceramic Research Institute, 196 Raja SC Malik Road, Kolkata 700032, India
}

Correspondence should be addressed to Jyotsna Dutta Majumdar, jyotsna@metal.iitkgp.ernet.in

Received 20 July 2011; Accepted 20 July 2011

Copyright (c) 2011 Jyotsna Dutta Majumdar et al. This is an open access article distributed under the Creative Commons Attribution License, which permits unrestricted use, distribution, and reproduction in any medium, provided the original work is properly cited.

Besides chemistry, processing route influences the microstructures and properties of metallic materials significantly. The emerging processing (fabrication) routes capable of tailoring the microstructures and hence properties of metallic materials include semisolid processing, spray forming, melt spinning, and laser materials processing. Although the present issue was initially proposed to present the articles based on all novel processing routes and its status on understanding the properties of materials, however, the topics and papers are not extensive representation of all the areas of advanced metallic materials processing. Furthermore, advanced processing of nonmetallic materials like polymeric materials is also included in the special issue. The special issue contains eight papers, out of them three articles present research works related to semisolid processing and five contributions on laser materials processing including one on processing of polymeric materials. The contributions from the authors who have expertise in different areas of materials processing are gratefully acknowledged. Needless to mention that without the time and efforts spent by the reviewers, the special issue would not have been presented in this form. The prompt reply and reminder by Ms. Doaa Shokry, Hindwai Publishers, is gratefully acknowledged.

Laser materials processing is a promising route, where a high-power laser beam is used as a source of heat for processing of materials. Faster processing speed, refinement and homogenization of microstructure, narrow heat affected zone, and processing of any materials are the notable advantages associated with laser materials processing. The first five articles are based on application of laser materials processing for the development of novel materials.
Laser surface cladding involves melting of clad material coating using laser beam and applying it on the surface with a minimum dilution at the interface. The first paper is on "Synthesis and characterization of high-entropy alloy $\mathrm{AlXFeCoNiCuCr}$ by laser cladding" by X. Ye et al. presented development of high entropy alloy (AlXFeCoNiCuCr) coating on AISI 1045 steel substrate by laser surface cladding technique. The characteristics of the clad layer in terms of microstructure, chemical composition and constituent phases are reported. The clad layers exhibited higher hardness at higher $\mathrm{Al}$ atomic content. $\mathrm{AlFeCoNiCuCr}$ clad layer also exhibited increased high temperature $\left(400^{\circ} \mathrm{C}-700^{\circ} \mathrm{C}\right)$ hardness.

Laser surface melting is a promising technique in improving the hardness, wear and corrosion resistance of surface by grain refinement and homogenization of microstructure. The second paper entitled "Metallurgical aspects of laser surface processing of PM Cr-V ledeburitic steel" by P. Jurči et al. reported on laser surface melting of Vanadis 6 ledeburitic steel. Laser surface melting and subsequent rapid solidifying led to softening of the material due to the presence of retained austenite which could be improved by subsequent tempering which was concluded to be a challenge for the future investigations. The mechanism of melting and solidification was presented in details.

Laser-assisted welding offers the advantages of development of weld zone with improved properties and flexibility in welding of a wide varieties of materials including dissimilar materials. The third paper concerns "Influence of welding parameters on weld formation and microstructure of dual laser beams welded T-joint of aluminum alloy" by $\mathrm{M}$. Li 
et al. In this paper, a detailed investigations of the effect of the distance between two laser beams $(d)$, welding speed $(v)$, laser power $(P)$, and the laser beam offset toward the stringer (BOF) on the weld appearance, microstructure, and hardness of the $1.8 \mathrm{~mm}$ thick 6061 aluminum alloy plates in T-joint configuration has been undertaken using dual lasers. It was observed that at the optimized parameters, the welded Tjoint showed good weld appearance without macrodefects; the microhardness of welds ranged from 75 to $85 \mathrm{HV}_{0.3}$, and the tensile strength was about $254 \mathrm{MPa}$ with the fracture at the heat affected zone (HAZ) on the stringer side.

Direct laser cladding involves building the near net shape component by laser melting of materials in the form of powder or wire and its subsequent application on a dummy substrate in a layer by layer fashion. In the fourth paper, application of DLD on the development of compositionally graded hip and femoral coupons with the cobalt ball on Ti-6Al$4 \mathrm{~V}$ femoral with a graded interface has been attempted using a continuous wave $\mathrm{CO}_{2}$ laser. Graded interface was developed by depositing a thin copper layer on Ti-6Al-4V substrate prior to multiple laser cladding of cobalt on it. Presence of copper interlayer was found to suppress the formation of brittle intermetallics of $\mathrm{Ti}$ and Co. The effect of process parameters on the microstructures, compositions and phases of the interface was studied in detail. Finally, the mechanical and electrochemical properties of the interface processed under optimum process parameters are reported.

The fifth paper on "Precise hole drilling in PMMA using $1064 \mathrm{~nm}$ diode laser CNC machine” by J. A. Abdulnabi et al. presented in brief the laser hole drilling of polymethylmethacrylate (PMMA) of $2.5 \mathrm{~mm}$ thickness using $1064 \mathrm{~nm}$ diode laser of $5 \mathrm{~W}$ output power. The effect of laser parameters on the drilling quality was investigated and supported by the predicted results of the analytical model.

Semisolid metal (SSM) processing is a unique manufacturing technique to fabricate near-net shape products for a variety of industrial applications. The objective is to achieve a semisolid structure which is free of dendrites and with the solid present in a near spherical form. In the present issue, three articles are presented on processing of materials by semisolid processing.

Application of electromagnetic stirring (EMS) is capable of modifying the microstructure of alloy before or during the forming process. In the sixth paper, H. H. Kim and C. G. Kang reported on "The fabrication of automobile components by applying electromagnetic stirring in semisolid process". In this article, the effect of electromagnetic stirring on the microstructure and properties of rheocasted A356 aluminum alloy was investigated in detail. It was observed that a significant improvement in mechanical property was achieved in the final product.

In the seventh paper, U. A. Curle et al. presented the a detailed description of industrial semisolid casting trials of aluminum A356 brake calipers in the paper entitled "Industrial semisolid rheocasting of aluminum A356 brake calipers". The process stability was determined by consecutive visual pass castings and determining the common defects between trials by X-ray examination and pressure testing of heat treated castings from the consecutive visual passed castings.

In the last paper of the special issue "The influence of prior natural aging on the subsequent artificial aging response of aluminium alloy A356 with respective globular and dendritic microstructures", H. Möller et al. presented an interesting observation on the effect of microstructural change associated with semisolid processing on its heat treatment behavior and its difference with the same for dendritic microstructure. In this paper, the influence of prior natural aging on the subsequent artificial aging response of aluminium alloy A356 with respective globular and dendritic microstructures has been described. It was concluded that the differences in microstructures (globular or dendritic) do not have a noteworthy effect on the heat treatment response. It is also shown that composition plays a major role in determining hardness regardless of the casting technique used.

In conclusion, it may be stated that all the articles in the present issue present original research efforts on advanced field of materials processing, especially on laser materials processing and rheocasting and would motivate the readers to consider research problem in this directions. Finally, we wish the issue to be a successful, popular, and useful one to the engineers, scientists, and researchers in the field of materials science and manufacturing technology.

Jyotsna Dutta Majumdar
Igor Smurov
Shoujin Sun
Indranil Manna



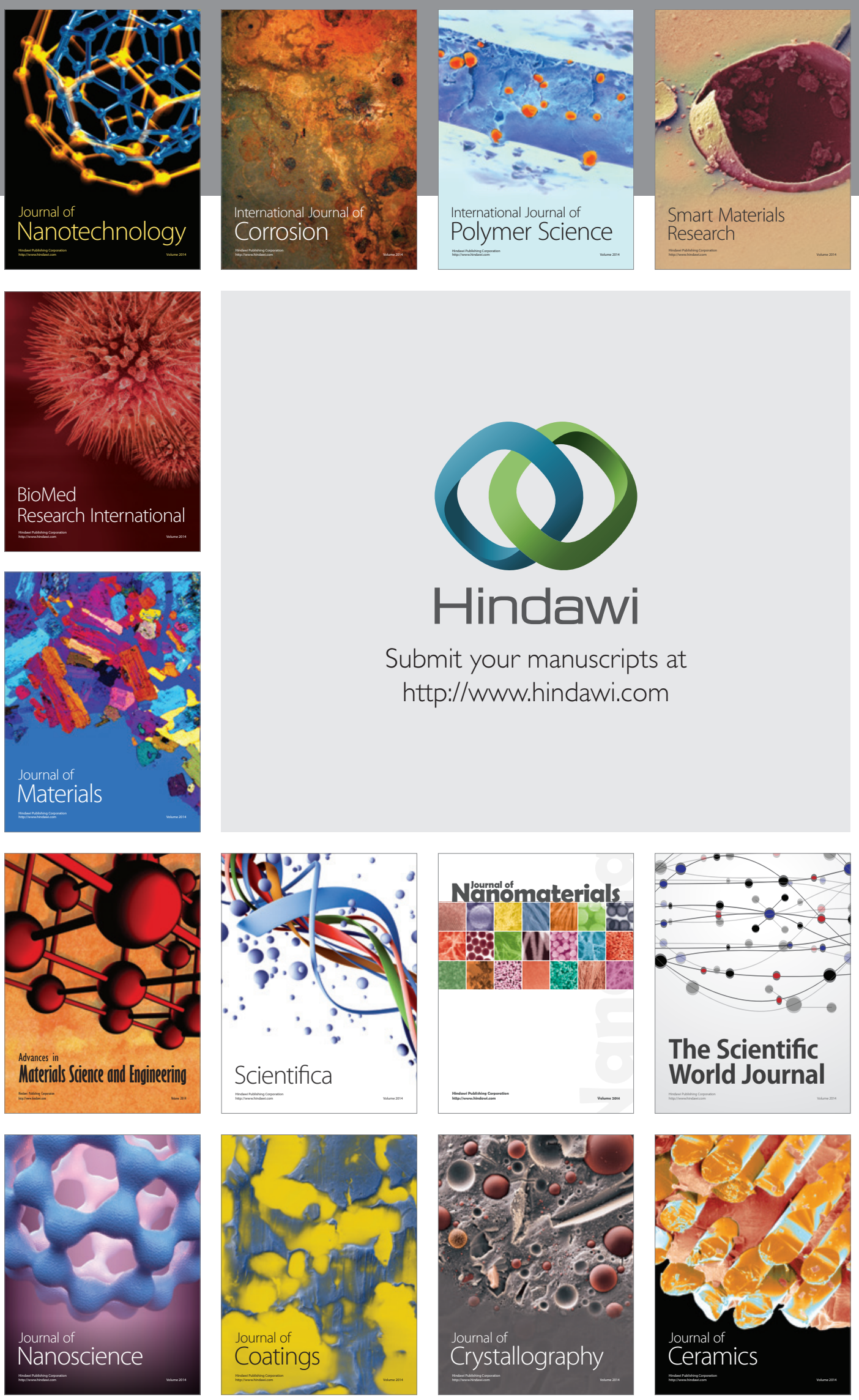

The Scientific World Journal

Submit your manuscripts at

http://www.hindawi.com

\section{World Journal}

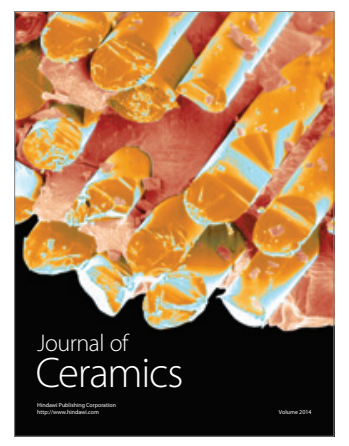

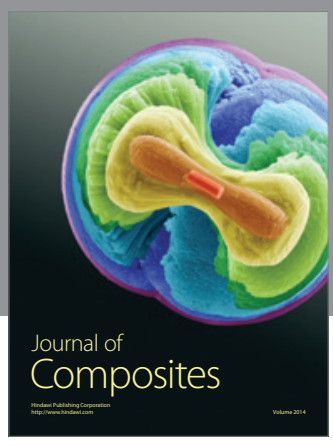
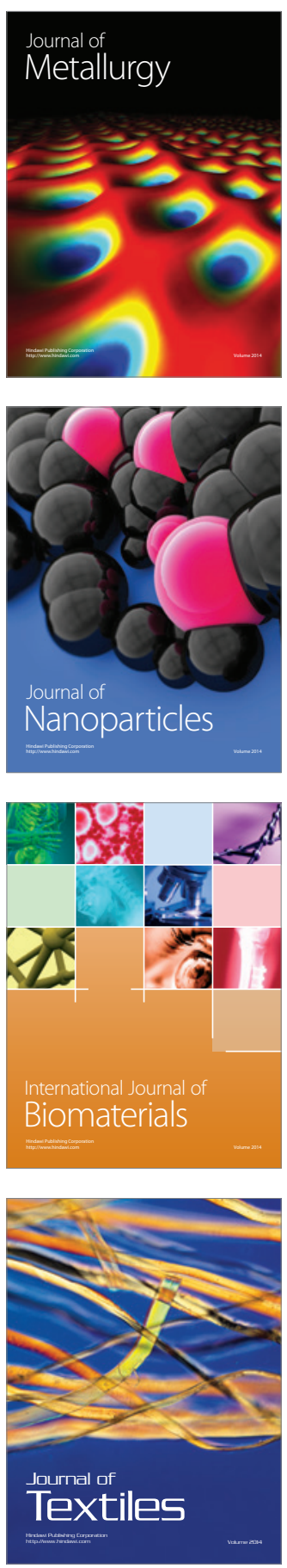